\title{
Concern on blood safety in case of swine flu
}

\section{Viroj Wiwanitkit}

Received: 19 June 2009 / Accepted: 18 August 2009

(C) Indian Society of Hematology and Transfusion Medicine 2009
Swine flu (atypical H1N1 infection) is a new emerging infectious disease that is the present discussed topic of medical scientists around the world [1-2]. It becomes pandemic disease around the world at present [1-2]. The presence of viremia in case infected with swine flu has raised present concerns about the safety of blood products for transfusion. Indeed, it is possible that the influenza virus, either classical or atypical viruses, can be transmitted via transfusion [3-5]. Hence, the concern on the blood donation is needed. It should be noted that the present protocol not to get donated blood from the cases with fever might not be sufficient because some swine flu infected cases show no fever. In addition, in the history of blood donor, a questionnaire to be included asking for history of travel specially air travel from countries with high number of H1N1 virus infection cases. Luckily, due to the nature of influenza, a respiratory tract infection, limited viremia can be observed. Conclusively, special concern and further study to verify the safety of blood product according to recent blood dona- tion protocol as well as virus inactivation procedures are necessary.

\section{References}

1. Senanayake SN (2009) Swine flu update: bringing home the bacon. Med J Aust 191(3):138-140

2. Wong RK (2009) Déjà vu: swine flu. Singapore Med J 50(7): 743-744

3. Likos AM, Kelvin DJ, Cameron CM, Rowe T, Kuehnert MJ, Norris PJ (2007) National Heart, Lung, Blood Institute Retrovirus Epidemiology Donor Study-II (REDS-II). Influenza viremia and the potential for blood-borne transmission. Transfusion 47(6): 1080-1088

4. Zou S (2006) Potential impact of pandemic influenza on blood safety and availability. Transfus Med Rev 20(3):181-189

5. Kreil TR, Unger U, Orth SM, Petutschnig G, Kistner O, Poelsler G, Berting A (2007) H1N1 influenza virus and the safety of plasma products. Transfusion 47(3):452-459

\footnotetext{
V. Wiwanitkit $(\square)$

Wiwanitkit House, Bangkhae, Bangkok - 10160,

Thailand

E-mail: wviroj@yahoo.com
} 